\title{
Identifying morphological traits associated with vegetative persistence in the perennial ryegrass (Lolium perenne L.) cultivar 'Grasslands Samson'
}

\author{
JESSICA R. O'CONNOR ${ }^{1 *}$, JAMES R. CRUSH ${ }^{2}$, and ZULFI JAHUFER ${ }^{1}$ \\ ${ }^{1}$ AgResearch, Grasslands Research Centre, Private Bag 11008, Palmerston North 4442, New Zealand \\ ${ }^{2}$ AgResearch, Ruakura Research Centre, 10 Bisley Road, Hamilton 3240, New Zealand \\ *Corresponding author email: jessica.oconnor@agresearch.co.nz
}

\begin{abstract}
Perennial ryegrass (Lolium perenne L.) vegetative persistence (maintained herbage growth and survival without reseeding) is an important economic trait for farmers in New Zealand as it decreases the frequency of reseeding pastures. Vegetative persistence is difficult to breed for due to a lack of long-term trials to record the complex interactions between plant genotype and the environment. In a long-term trial, a genetic shift in the sown cultivar population could occur as individual plants with advantageous traits outcompete other plants and survive. The objectives of our study were to investigate the occurrence of a potential genetic shift in a sample (30 plants) of a persistent population of 'Grasslands Samson' perennial ryegrass. Persistent plants were collected from a nine-year-old trial at Poukawa, Hawke's Bay. To identify a genetic shift, these plants were compared to a sample of 30 plants sourced from commercial seed of 'Grasslands Samson'. This study estimated genotypic variation within and between the populations for eight morphological traits after 10 weeks' growth under glasshouse conditions. Phenotypic and genotypic correlations between the traits were estimated. Results showed that the persistent population had significantly $(\mathrm{P}<0.05)$ greater means for tiller number, reproductive tiller number, lamina sheath length, and dry weight. Future research studying these traits across farm environments would improve our understanding of their roles in vegetative persistence of ryegrass.
\end{abstract}

Keywords: Perennial ryegrass, vegetative persistence, genotypic variation, morphology

\section{Introduction}

Perennial ryegrass (Lolium perenne L.) in New Zealand is used primarily as a cost-effective pasture grass supporting the grazing requirements of beef cattle, dairy cows, sheep, and deer (White \& Hodgson 1999; Romera et al. 2017). It is a perennial species due to its prolific tillering habit. Plants continuously produce daughter tillers from the leaf axils of mature tillers. Perennial ryegrass is genetically self-incompatible and suffers severe inbreeding depression (Lee et al. 2012). Because of its out-breeding habit, there are high levels of genetic variation within this species resulting in diverse plant morphologies ranging from small turf types (Dracatos et al. 2009), to high yielding pasture plants (Easton et al. 2002). Cultivars of perennial ryegrass consist of related but genetically different individuals (Lee et al. 2012). Therefore, genetic improvement during cultivar development focusses on improving the mean performance of the population.

In New Zealand's perennial ryegrass breeding programmes, improved vegetative persistence is an important objective in cultivar development. Vegetative persistence includes the survivorship of plants and the continued stability of dry matter yields of sown populations without reseeding (Parsons et al. 2011). Genetic improvement of this trait is beneficial to New Zealand farmers. Significant cost savings associated with less frequent regrassing are realised if a cultivar maintains yields and survives longer (Malcolm et al. 2014). Phenotypes that contribute to vegetative persistence are difficult to identify, measure and select for due to the significant and complex interactions between plant genotype and the environment affecting the resulting phenotype (Clark 2011; Chapman et al. 2015a).

Results from short-term trials (six months - three years) suggest some trait associations with improved vegetative persistence. These include infection with the endophytic fungus (Epichloë festucae var. lolii) to deter insect herbivory (Easton et al. 2001; Hume \& Sewell 2014), disease resistance to crown rust (Puccinia coronata f.sp. lolii) improving survival of asexual tillers (Muylle et al. 2005; Easton et al. 2011), and greater tiller density increasing plant competitiveness for resources and subsequent survival of environmental fluctuations (Jewiss 1972; Westoby 1984; Parsons et al. 2011; Tozer et al. 2014).

Long-term field trials, such as the cultivar comparison trial at Poukawa in Hawke's Bay (sown in 2005) are a rare resource in New Zealand (Lee et al. 2012; Chapman et al. 2015b). Assessing plant genetic diversity changes occurring in long-term field trials provides opportunities to identify phenotypes 
associated with vegetative persistence (Parsons et al. 2011). Over time, plants that had advantageous phenotypes for survival and growth without reseeding may have outcompeted and survived better than individuals with less advantageous phenotypes (Parsons et al. 2011). This may significantly shift the mean trait expression of the remaining population. There is some evidence that a genetic shift could have occurred at the long-term field trial in Poukawa. Chapman et al. (2015b) found dry matter yield data collected in the first three years during the Poukawa trial significantly correlated with data from years seven to eight ( $\mathrm{r}=0.818-0.685$; respectively). However, in year 10 there was no significant correlation $(r=0.392)$ with years one to three. Whether this difference was due to a genetic shift has been studied. Cashman (2014) was not able to distinguish between 'aged' and 'seed' accessions of any plants sampled directly from the 12 cultivars at the Poukawa site assessed in a spaced plant trial in Hamilton. Conversely, O'Connor et al. (2020) did identify additive genetic differences associated with grazing avoidance traits between half-sib families generated from plants of 'Grasslands Samson' sourced from Poukawa and their commercially bought seed counterparts in a grazed row field trial undertaken in Palmerston North. Faville et al. (2020) also compared survivor (four and six years) ryegrass plants in regional trials to remnant seed plants focussing on identifying population genetic changes using microsatellite markers (SSRs). Data on lamina morphology (lamina length, lamina thickness, leaf area, and tiller appearance rate showed that survivors had shorter lamina lengths than plants grown from seed in year four but not in year six. They attributed this result to the year four plants being exposed to hotter and dryer growth conditions prior to sampling compared to the year six plants.

Mature plants have been assessed for genetic shifts in persistent populations but genotypic trait differences of tiller morphologies of plants that have persisted in the field have not previously been assessed. Identifying tiller morphological traits associated with a genetic shift in plants extracted from long-term trials would better inform plant breeders about traits associated with growth in persistent populations (Parsons et al. 2011; Tozer et al. 2014). In this trial, plants from persistent survivors, and commercially bought seed of the cultivar 'Grasslands Samson' were assessed for eight morphological traits after 10 weeks' growth in a glasshouse pot trial. The objectives of this study were to: (1) estimate genotypic variation within each population for each of the traits; (2) compare the mean for each trait between the two populations; (3) identify associations between traits and compare possible changes in trait associations over time.

\section{Materials and methods Germplasm}

In May 2014, 60 'persistent' perennial ryegrass plants of the cultivar 'Grasslands Samson' (with AR1 endophyte) were collected from a grazed cultivar comparison trial established in April 2005 at Poukawa Research Station, Hawke's Bay (39 $76^{\circ}$ S, 176 $72^{\circ}$ 'E). The Poukawa Research Station area is on Okawa silty loam soil and experiences warm temperatures, high sunshine hours in summer and frequent occurrence of droughts (Chapman et al. 2015b). Single tillers were grown in sand trays in a glasshouse for a week to establish roots. Rooted tillers were transplanted into 2-L planter pots with 18-month Osmocote ${ }^{\mathrm{TM}}$ soil mix. At the same time, a random sample of seeds bought from Farmlands in Palmerston North of the original cultivar 'Grasslands Samson' infected with AR1 endophyte were sown into seed trays in the glasshouse establishing 60 plants. After four weeks' growth, plants with three or more tillers were transplanted into 2-L planter pots with 18 month Osmocote ${ }^{\mathrm{TM}}$ soil mix. All plants were maintained outdoors for two years at AgResearch Grasslands, Palmerston North (40⒉ $\left.1^{\prime} \mathrm{S}, 175^{\circ} 37^{\prime} \mathrm{E}\right)$, with periodic trimming.

In July 2016, 30 individual plants were randomly sampled from each population for the study. Eight clonal tillers were taken from each genotype and planted separately into sterilised sand to allow growth of roots. After seven days, five clones from each plant were removed from the sand and planted in pots with six-month Osmocote ${ }^{\mathrm{TM}}$ soil mix. The experiment was established in August 2016 in a glasshouse at the Ruakura Research Centre, Hamilton, New Zealand $\left(37^{\circ} 77^{\prime} \mathrm{S}, 175^{\circ} 30^{\prime} \mathrm{E}\right)$. In the glasshouse, a total of 300 plants were arranged in a randomised complete block design with five replicates (five clones) for each of the 60 genotypes. The average temperature of the glasshouse over the trial period was $17.4^{\circ} \mathrm{C}$ during the day and $11.5^{\circ} \mathrm{C}$ at night. Plants were grown for 10 weeks without defoliation and were well watered using an overhead watering system.

\section{Measurements}

After 10 weeks' growth, data collection was carried out once on eight morphological traits for each plant (Table 1). Lamina length, lamina sheath length, lamina width, and lamina thickness were measured on the oldest green lamina (leaf) of three tillers from each plant.

\section{Data analysis}

All morphological trait data were analysed using analysis of variance (ANOVA) in GenStat 18th edition (VSN 2015). Data were analysed separately for each trait to provide means, calculate $\mathrm{F}$ ratio values and estimate least significant differences (L.S.D) at $\mathrm{P}<0.05$ 
Table 1 The eight morphological traits measured after 10 weeks' growth, their abbreviation (Abb.), the number of measurements per plant (No.), and measurement methods.

\begin{tabular}{|c|c|c|c|}
\hline Trait & Abb. & No. & Description \\
\hline Total no. tillers & TN & 1 & Total number of live tillers \\
\hline No. reproductive tillers & $\mathrm{RT}$ & 1 & $\begin{array}{l}\text { Number of reproductive tillers. Identified by rounded sheaths and presence of } \\
\text { internodes in the pseudostem. }\end{array}$ \\
\hline Reproductive tiller (\%) & $\mathrm{RP}$ & 1 & $\mathrm{RT} / \mathrm{TN} \times 100$ \\
\hline Lamina length & LL & 3 & Distance $(\mathrm{cm})$ between ligule and lamina tip \\
\hline Lamina sheath length & SL & 3 & Distance $(\mathrm{cm})$ between the base of the tiller (stem apex) and the auricles. \\
\hline Lamina width & LW & 3 & Width $(\mathrm{mm})$ at midpoint of lamina \\
\hline Lamina thickness & LT & 3 & Calliper* thickness $(\mathrm{mm})$ of lamina blade two $\mathrm{cm}$ from ligule \\
\hline Dry weight & DW & 1 & Weight $(\mathrm{g})$ of oven dried $\left(80^{\circ} \mathrm{C}\right.$ for 72 hours) above ground biomass cut at soil level. \\
\hline
\end{tabular}

* Digital Mitutoyo callipers (Mitutoya Corporation, Sakado, Japan).

Separate analyses were carried out on each population to analyse within population variation for each trait. The four traits with three measurements per plant (Table 1) were analysed using replicate and sample number as block and plant genotype as treatment. Traits with only one measurement per plant were analysed by using replicate as block and plant genotype as treatments. To test the homogeneity of variance of the two populations for each trait, Bonett's test statistic was used in Minitab (Bonett 2006; Anon. 2010). Results were considered significantly different if $\mathrm{P}<0.05$ for both ANOVA and Bonett's test statistic. Only traits that showed significant $(\mathrm{P}<0.05)$ genotypic variation within populations were further assessed in principal components analysis (PCA).

Principal components analysis was conducted on the 30 plant-by-five trait mean matrix generated from the persistent and original populations using the statistical software DeltaGen (Jahufer \& Luo 2018). The biplots generated in DeltaGen provide a graphical display of the variation present among the 30 plants evaluated within the persistent and original populations and the relationships among the five traits. Genetic correlation coefficients were estimated using plant-trait matrices for traits only with significant $(\mathrm{P}<0.05)$ genotypic variation in each population. The analysis was conducted in DeltaGen, using the Pearson correlation option.

\section{Results}

\section{Within population variation}

Results of ANOVA showed significant differences $(\mathrm{P}<0.05)$ (Table 2) within each population for total number of tillers $(\mathrm{TN})$, lamina length (LL), lamina sheath length (SL), lamina width (LW) and lamina thickness (LT). Within each population number of reproductive tillers (RT), reproductive tiller \% (RP) and dry weight (DW) did not differ significantly.

\section{Multivariate trait analysis}

Principal component (PC) analysis of the accessionby-trait best linear unbiased estimator (BLUE) mean matrices generated biplots for each population are shown in Figure 1. The correlation structure among the traits in each biplot is indicated by the directional vectors. The PCA for the original population showed principal components $\mathrm{PC} 1$ and $\mathrm{PC} 2$ accounted for $38.7 \%$ and $32.7 \%$ of the variation respectively (Figure 1a). The biplot showed a positive association (angles between the directional vectors are less than $90^{\circ}$ ) between lamina thickness (LT) and lamina width (LW). Lamina length (LL), total no. of tillers (TN), and lamina sheath length (SL) also showed positive associations. SL showed a negative association (angles between the directional vectors are more than $90^{\circ}$ ) with LT and LW (Figure 1a). Pairwise Pearson correlation coefficients showed significant $(\mathrm{P}<0.05)$ association between LL and LW, LL and SL, and LW and LT (Table 3). Other trait associations were not significant $(\mathrm{P}>0.05)$.

The persistent population principal components analysis showed that PC1 accounted for $42.7 \%$ and PC2 $27.4 \%$ of the variation (Figure 1b). The biplot showed a positive association between the traits total number of tillers (TN), lamina sheath length (SL), and lamina length (LL). Lamina thickness (LT) was positively associated with lamina width (LW) but negatively associated with SL and TN. Pairwise Pearson correlation coefficients showed significant $(\mathrm{P}<0.05)$ association between TN and LL, TN and SL, LL and LW, LL and SL, and LW and LT (Table 3). Other trait associations were not significant $(\mathrm{P}>0.05)$.

\section{Between population variation}

Significant $(\mathrm{P}<0.05)$ phenotypic variation was observed between the persistent and original populations for four of the eight traits. Persistent population means were 
Table 2 Analysis of variance (ANOVA) for each trait within each population. Mean, range, L.S.D ${ }_{0.05}$ and F pr are presented.

\begin{tabular}{|c|c|c|c|c|c|}
\hline Population & Trait & Mean & Range & L.S.D 0.05 & $\mathrm{~F} \mathrm{pr}$ \\
\hline \multirow[t]{8}{*}{ Original } & $\mathrm{TN}$ & 24.06 & $16.60-39.06$ & 13.97 & $0.04^{*}$ \\
\hline & $\mathrm{RT}$ & 6.67 & $4.60-10.00$ & 6.29 & $0.99^{\mathrm{NS}}$ \\
\hline & $\mathrm{RP}(\%)$ & 28.02 & $13.70-39.80$ & 19.75 & $0.63^{\mathrm{NS}}$ \\
\hline & LL (cm) & 20.51 & $14.99-26.23$ & 3.1 & $<0.001^{\star \star *}$ \\
\hline & $\mathrm{SL}(\mathrm{cm})$ & 3.69 & $2.43-4.77$ & 0.72 & $<0.001^{\star * *}$ \\
\hline & $\mathrm{LW}(\mathrm{mm})$ & 3.58 & $2.75-4.50$ & 0.42 & $<0.001^{\star * *}$ \\
\hline & $\mathrm{LT}(\mathrm{mm})$ & 0.226 & $0.177-0.267$ & 0.02 & $<0.001^{* * *}$ \\
\hline & $\mathrm{DW}(\mathrm{g})$ & 2.05 & $1.27-3.58$ & 1.54 & $0.60^{N S}$ \\
\hline \multirow[t]{8}{*}{ Persistent } & $\mathrm{TN}$ & 26.72 & $13.20-44.60$ & 14.9 & $0.01^{* *}$ \\
\hline & $\mathrm{RT}$ & 7.89 & $4.00-10.80$ & 6.53 & $0.96^{\mathrm{NS}}$ \\
\hline & $\mathrm{RP}(\%)$ & 29.8 & $18.10-44.80$ & 17.45 & $0.25^{\mathrm{NS}}$ \\
\hline & $\mathrm{LL}(\mathrm{cm})$ & 20.64 & $14.60-27.13$ & 2.93 & $<0.001^{\star \star \star}$ \\
\hline & $\mathrm{SL}(\mathrm{cm})$ & 3.93 & $3.08-4.99$ & 0.76 & $<0.001^{* * *}$ \\
\hline & $\mathrm{LW}(\mathrm{mm})$ & 3.65 & $3.01-4.17$ & 0.39 & $<0.001^{\star * *}$ \\
\hline & $\mathrm{LT}(\mathrm{mm})$ & 0.225 & $0.200-0.263$ & 0.02 & $<0.001^{* * *}$ \\
\hline & DW (g) & 2.42 & $1.12-3.79$ & 1.89 & 0.50 \\
\hline
\end{tabular}

NS NS (not significant) $=\mathrm{P}>0.05 ;{ }^{*}=\mathrm{P}<0.05 ;{ }^{* \star *}=\mathrm{P}<0.001$

greater for TN $(+10.0 \%)$, RT $(+15.5 \%)$, SL $(+6.1 \%)$, and DW $(+15.7 \%)$ when compared to the original population means. RP, LL, LW, and LT were not significantly different $(\mathrm{P}>0.05)$ between the populations (Table 4). The standard deviation ratio was found to be 1:1 between the populations for TN, RT, RP, LL, SL, and LW. However significant $(\mathrm{P}=0.01)$ differences between standard deviations of DW data were found between the populations (Bonett's test, Table 4).

Table 3 Pearson's correlation coefficient and significance between the traits total number of tiller (TN), lamina length (LL), lamina width (LW), lamina thickness $(\mathrm{LT})$, and lamina sheath length (SL) for the original population and the persistent population.

\begin{tabular}{lccccc}
\hline Population & Traits & TN & LL & LW & LT \\
\hline Original & LL & $0.32^{\mathrm{NS}}$ & & & \\
& LW & $0.21^{\mathrm{NS}}$ & $0.38^{\star *}$ & & \\
& $\mathrm{LT}$ & $0.09^{\mathrm{NS}}$ & $0.06^{\mathrm{NS}}$ & $0.68^{\star \star *}$ & \\
& $\mathrm{SL}$ & $0.23^{\mathrm{NS}}$ & $0.46^{*}$ & $-0.05^{\mathrm{NS}}$ & $-0.30^{\mathrm{NS}}$ \\
\hline Persistent & LL & $0.42^{*}$ & & & \\
& LW & $0.15^{\mathrm{NS}}$ & $0.57^{\star * *}$ & & \\
& $\mathrm{LT}$ & $-0.03^{\mathrm{NS}}$ & $0.04^{\mathrm{NS}}$ & $0.44^{*}$ & \\
& $\mathrm{SL}$ & $0.38^{*}$ & $0.56^{\star * *}$ & $0.03^{\mathrm{NS}}$ & -0.02 \\
\hline
\end{tabular}

${ }^{\text {NS NS }}$ (not significant) $=\mathrm{P}>0.05 ;{ }^{*}=\mathrm{P}<0.05 ;{ }^{* \star}=\mathrm{P}<0.01 ;{ }^{* \star \star}=\mathrm{P}<0.001$

\section{Discussion}

Previous studies on perennial ryegrass persistence compared half-sib families generated from seed collected from persistent populations sourced from Poukawa, to their original cultivar and identified a genetic shift occurring in 'Grasslands Samson' using visual scores (O'Connor et al. 2020). However, Faville et al. (2020) were not able to consistently identify genetic shifts occurring between survivor plants (four and six years old) of Alto and Nui from their remnant

Table 4 Mean values of the persistent and original populations for the eight traits measured. Least significant difference (L.S.D. ${ }_{0.05}$ ) between means, significance level (F pr), and Bonett's test statistic are presented.

\begin{tabular}{lrcccc}
\hline Trait & Original & Persistent & L.S.D..$_{0.05}$ & F pr & $\begin{array}{c}\text { Bonett's } \\
\text { test }\end{array}$ \\
\hline TN & 24.06 & 26.72 & 2.63 & $0.05^{*}$ & $0.42^{\mathrm{NS}}$ \\
RT & 6.67 & 7.89 & 1.17 & $0.04^{*}$ & $0.53^{\mathrm{NS}}$ \\
RP $(\%)$ & 28.02 & 29.80 & 3.38 & $0.30^{\mathrm{NS}}$ & $0.22^{\mathrm{NS}}$ \\
LL $(\mathrm{cm})$ & 20.51 & 20.64 & 0.55 & $0.63^{\mathrm{NS}}$ & $0.50^{\mathrm{NS}}$ \\
SL $(\mathrm{cm})$ & 3.69 & 3.93 & 0.13 & $<0.001^{\star \star *}$ & $0.80^{\mathrm{NS}}$ \\
LW $(\mathrm{mm})$ & 3.58 & 3.65 & 0.07 & $0.07^{\mathrm{NS}}$ & $0.89^{\mathrm{NS}}$ \\
LT $(\mathrm{mm})$ & 0.226 & 0.225 & 0.004 & $0.53^{\mathrm{NS}}$ & $0.40^{\mathrm{NS}}$ \\
DW $(\mathrm{g})$ & 2.04 & 2.42 & 0.31 & $0.02^{*}$ & 0.01 \\
\hline
\end{tabular}

${ }^{* \star} \mathrm{NS}$ (not significant) $=\mathrm{P}>0.05 ;{ }^{*}=\mathrm{P}<0.05 ;{ }^{* *}=\mathrm{P}<0.01 ;{ }^{* \star *}=\mathrm{P}<0.001$ 
A) ORIGINAL

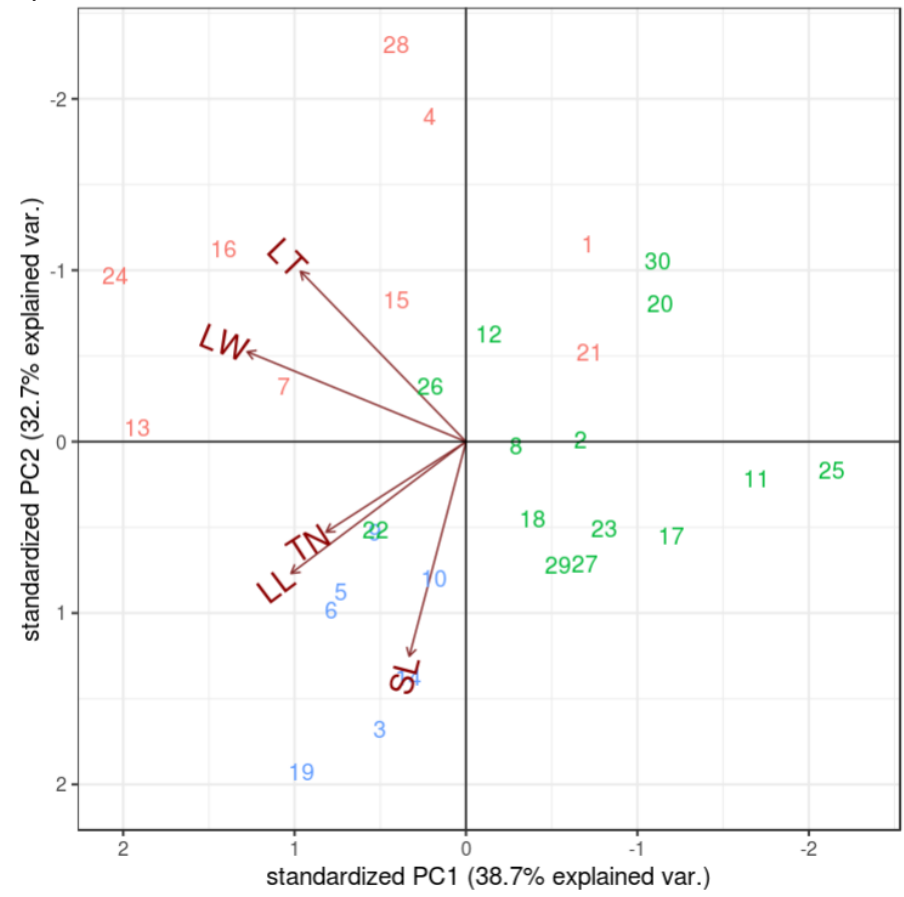

B) PERSISTENT

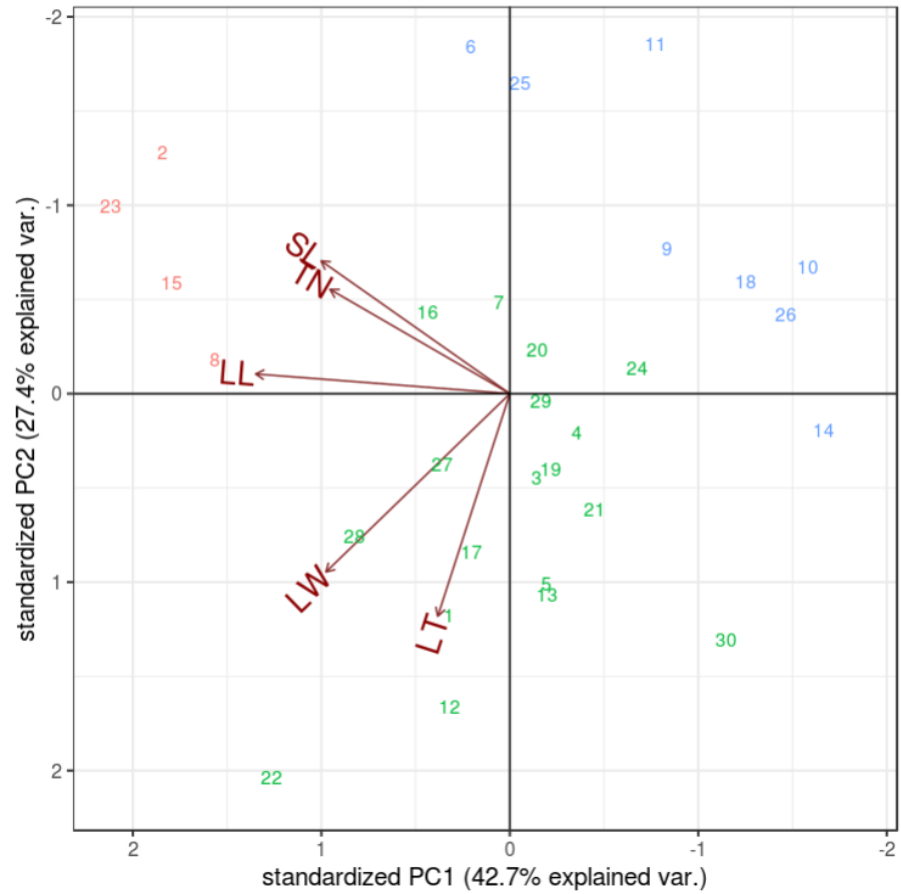

Figure 1 Biplots generated using standardised Best Linear Unbiased Estimate values for five traits measured from the 30 perennial ryegrass genotypes in each of the1: a) original population; and b) persistent population. Traits are indicated by the directional vectors: Total number of tillers (TN), lamina length (LL), lamina sheath length (SL), lamina width (LW), and lamina thickness (LT). 
seed using SSRs and lamina morphology traits. The current glasshouse trial aimed to identify tiller morphological differences indicating a genetic shift occurring between a sample of 30 genotypes from a persistent population of 'Grasslands Samson' perennial ryegrass of a long-term trial and 30 genotypes of the same cultivar grown from seed (representing the original population). Significant $(\mathrm{P}<0.05)$ phenotypic differences between the populations for total number of tillers (TN), number of reproductive tillers (RT), lamina sheath length (SL), and dry weight (DW) indicate that a genetic shift had occurred in the ryegrass population in the long-term field trial at Poukawa.

\section{Total number of tillers (TN)}

The persistent population had significantly greater TN compared to the original population and there was significant variation within each population. Greater tiller number could contribute to vegetative persistence of an individual plant by increasing the number of asexually propagating clones (Jewiss 1972). More clones dispersing progressively across the field could decrease the risk of loss of the entire genotype from abiotic and biotic stresses (such as insect herbivory and pugging) leading to greater survival long term (Bahmani et al. 2003; Parsons et al. 2011). Over time, a pasture is constantly re-establishing through propagation of vegetative tillers after pugging events, defoliation, and death of neighbouring plants. Being able to outcompete other individuals in the pasture for these spaces through faster propagation of tillers would increase the chances of survival for that genotype. Lee et al. (2017) found individual ryegrass plants that had accumulated $>15$ tillers $5-6$ months after sowing (late winter/early spring) were more likely to survive compared to plants with $<15$ tillers.

Greater tiller appearance rate with consequently greater tiller number would be advantageous during pasture establishment. Pastures established with diploid perennial ryegrass cultivars in New Zealand are sown at rates of $18-25 \mathrm{~kg} / \mathrm{ha}$ (Lee et al. 2018). Many ryegrass individuals do not survive after initial germination due to interplant competition for resources (Jewiss 1972; Westoby 1984). Past research has found that perennial ryegrass survival after seven weeks was between 41$69 \%$ at a sowing rate of $18 \mathrm{~kg} / \mathrm{ha}$ (Lee et al. 2017). The sample of individuals in the 'persistent' population that survived the initial intense interplant competition (sowing rate $20 \mathrm{~kg} / \mathrm{ha}$ at Poukawa; Chapman et al. 2015) of establishment may have had a genetic advantage in being able to develop tillers faster than other plants in the population during establishment. However, Lee et al. (2018) found no genetic shift between perennial ryegrass populations using simple sequence repeat (SSR) analysis under different sowing rates $(12 \mathrm{~kg} /$ ha and $30 \mathrm{~kg} / \mathrm{ha}$ ) four years after establishment. This result indicated that for the cultivars 'Grasslands Nui', 'Commando', 'Alto', and 'Halo' the increased mortality associated with the higher sowing rate did not result in a genetic shift for the cultivars used in their trial, i.e. mortality was random. Our results showing a genetic shift in the persistent population for TN, could be attributed to the cultivar used ('Grasslands Samson'). Past studies on persistent populations have shown genetic shifts to be cultivar dependant. In a grazed row field trial in Palmerston North, O'Connor et al. (2020) found the direction of genetic shift differed between cultivars when comparing data of half-sib families generated from persistent populations of 'Grasslands Samson' and 'Commando' sampled from the Poukawa site. The study found 'Grasslands Samson' was more subject to directional selection. Cashman et al. (2016) assessed phenotypic characters of 'aged' and 'seed' accessions of European and New Zealand ('Alto', 'Arrow', and 'Bealey') cultivars in a sown plot field trial in Fermoy, Ireland. They also found the direction and magnitude of change between 'aged' and 'seed' accessions was cultivar dependant. The stringency of selection applied to cultivars during breeding would affect the variation present within each cultivar and subsequent potential for genetic shifts to happen in the field.

Even though the persistent population has a greater total number of tillers (TN) and reproductive tiller number (RT), the proportion of reproductive tillers (RP) was similar for both original (28\%) and persistent populations $(29.8 \%)$. This result shows that the persistent population was investing a similar proportion of resources into reproductive development as the original population. The ratio of reproductive tillers to vegetative tillers has been considered indicative of the plant's ability to perennate as vegetative tillers survive after reproductive tillers flower, set seed and die (Jewiss 1972; Wilkins \& Humphreys 2003). There was no evidence from the RP data for any variation between the populations in producing more reproductive tillers or earlier development of reproductive tillers. This indicates that the populations have similar timing in initiating reproductive development, and that their heading dates would be similar.

\section{Lamina morphology associations}

Trait associations generated from PCA analyses, and Pearson correlation coefficients show some similar associations. However, the associations presented in the PCA biplots between TN and other traits for the original population should be interpreted with care. Differences in associations between the PCA biplots and the Pearson correlation coefficients can occur as the biplot doesn't represent the multi-dimensional nature of the PCA vectors. The direction of the TN vector variation 
could be affected by another principal component not easily presented in our biplots.

Biplots showed SL was positively associated with LL for both populations with significant Pearson correlation coefficient values of 0.46 and 0.56 respectively. The positive association between SL and LL has been reported previously for diploid perennial ryegrass cultivars, with greater correlation coefficient values of 0.75 (Griffiths et al. 2016) and 0.74 (Sartie et al. 2009). The positive association between SL and LL are likely due to physiological aspects of leaf growth (Sartie et al. 2009; Griffiths et al. 2016). As new leaves develop, the top of the lamina blade extends out of the older leaf sheath exposing it to light. Subsequently, cell division slows in the meristem at the leaf base determining the number of cells and the resulting length of the lamina blade (Durand et al. 1999; Verdenal et al. 2008). It was expected that due to the positive association between SL and LL that a genetic shift would have happened for both traits. Instead, no significant differences in LL were detected between the two populations, while SL was significantly greater in the persistent population. Some independent genetic control of SL over LL has been previously identified where selecting for LL in perennial ryegrass led to a disproportional response to SL (Hazard et al. 1996).

\section{Lamina sheath length (SL) and tiller types}

A positive association was identified in principal component analysis between SL and TN in both populations, but significant correlation coefficients were only observed between these traits in the persistent population. The greater values of the traits TN and SL in the persistent population could be caused by SL regulating tiller development. Longer lamina sheaths decrease the amount of light reaching the base of leaf axils, slowing the initiation of tiller development (Davies et al. 1983; Westoby 1984). In the absence of leaf canopy closure, longer SL could supress vegetative tiller growth leading to two outcomes: changing the assimilate partitioning of carbon from vegetative tiller development into the growth of reproductive tillers (Parsons \& Robson 1981a; Barre et al. 2018); and assimilating carbon in roots before the onset of summer when abiotic stresses (such as drought) (Parsons \& Robson 1981b) are more likely to occur.

However, SL impact on vegetative survival may be prohibitive during the months where reproductive tiller development is not occurring. During the winter, nonsignificant differences between cultivar sheath lengths have been found (Griffiths et al. 2016), and under laxer grazing management regimes, a possible negative effect of shading by longer SL may prevent tiller formation and regrowth decreasing vegetative persistence (Davies et al. 1983). Better understanding of the role of this trait in seasonal tiller formation is needed before greater SL can be associated with greater vegetative persistence.

\section{Dry weight}

Association of tiller number with dry weight (DW) has previously been described in conjunction with size/ density compensation where a greater number of tillers does not always equate to greater DW when compared to plants with larger sized tillers (Matthew et al. 1995; Griffiths et al. 2016). In this study, the short time period between single tiller establishment and data collection did not allow for canopy closure and size/density compensation was not applicable. Consequently, greater number of tillers lead to greater dry weights.

\section{Within population variation}

A hypothesis of this study was that the persistent plants would show less phenotypic variation for the morphological traits measured. The reasoning was that after nine years in the field only a proportion of plants with advantageous phenotypes would survive decreasing the variability of plant morphology observed (Parsons et al. 2011). Bonett (2006) test statistic showed that persistent plants had significantly greater phenotypic variation for DW only, and that a reduction in phenotypic variation was not observed in the persistent population for the other traits measured. Failure to detect reduced phenotypic variation between the populations for most of the traits could be due to a relatively low sample of individuals representing each population. However, Faville et al. (2020) also found no significant differences in within population allele frequencies after sampling 90 plants from 32 perennial ryegrass populations over six years under dairy grazing using SSR analysis.

\section{Conclusions/Practical implications/Relevance}

In this glasshouse trial, trait differences in tiller morphologies were detected between the persistent population and original population of the ryegrass cultivar 'Grasslands Samson'. Results show evidence of a genetic shift taking place as persistent plants had significantly greater means for total number of tillers, number of reproductive tillers, lamina sheath length, and dry weight. Increased total tiller number was a product of tiller appearance rate which would be advantageous in the establishment phase of the pasture and the ongoing survival of individual genotypes in the field. The persistent population did not show reduced genotypic variation in traits measured compared to the original population. Future investigation into the role of lamina sheath length regulation in seasonal tiller number and appearance rate associated with vegetative persistence, would be beneficial for plant breeders to understand traits associated with vegetative persistence. 


\section{ACKNOWLEDGEMENTS}

The authors would like to acknowledge AgResearch for funding of this project through the SSIF Forage Value programme, (Contract No. A19054) and for the use of the facilities at Ruakura campus to complete this work. We also want to share our gratitude for Lily Ouyang in helping with this experiment.

\section{REFERENCES}

Anon. 2010. Minitab 17 Statistical Software: State College, PA, USA

Bahmani I, Thom ER, Matthew C, Hooper RJ, Lemaire G. 2003. Tiller dynamics of perennial ryegrass cultivars derived from different New Zealand ecotypes: effects of cultivar, season, nitrogen fertiliser, and irrigation. Australian Journal of Agricultural Research 54: 803817. https://doi.org/10.1071/AR02135

Barre P, Ruttink T, Muylle H, Lootens P, Sampoux JP, Rohde A, Combes D, Roldán-Ruiz I. 2018. Natural diversity in vegetative and reproductive investments of perennial ryegrass is shaped by the climate at the place of origin. Grass and Forage Science 73: 193205. https://doi.org/10.1111/gfs.12304

Bonett DG. 2006. Robust confidence interval for a ratio of standard deviations. Applied Psychological Measurement 30: 432-439. https://doi. org/10.1177/0146621605279551

Cashman PA. 2014. Differential productivity and persistency responses to simulated and animal grazing of perennial ryegrass genotypes. Unpublished thesis, The Queen's University of Belfast, UK.

Cashman PA, Gilliland TJ, McEvoy M, Watson S, O'Donovan M. 2016. Changes in plant morphological expression in 12 perennial ryegrass cultivars following frequent and infrequent cutting management. Journal of Agricultural Science 154: 456-471. https://doi. org/10.1017/S0021859615000386

Chapman DF, Edwards GR, Stewart AV, McEvoy M, O'Donovan M, Waghorn GC. 2015a. Valuing forages for genetic selection: what traits should we focus on? Animal Production Science 55: 869-882. https://doi. org/10.1071/AN14838

Chapman DF, Muir PD, Faville M. 2015b. Persistence of dry matter yield among New Zealand perennial ryegrass (Lolium perenne L.) cultivars: insights from a long-term data set. Journal of New Zealand Grasslands 77: 177-184. https://doi.org/10.33584/ jnzg.2015.77.463

Clark D. 2011. Changes in pastoral farming practices and pasture persistence-a review. Grassland Research and Practice Series 11: 7-13.

Davies A, Evans ME, Exley JK. 1983. Regrowth of perennial ryegrass as affected by simulated leaf sheaths. The Journal of Agricultural Science 101: 131137. https://doi.org/10.1017/S0021859600036455
Dracatos P, Dumsday J, Stewart A, Dobrowolski M, Cogan N, Smith K, Forster J. 2009. Genetic diversity in Australasian populations of the crown rust pathogen of ryegrasses (Puccinia coronata f.sp lolii). In: Yamada T, Spangenberg G (Eds), Molecular Breeding of Forage and Turf. New York: Springer, pp. 275-284. https://doi.org/10.1007/978-0-38779144-9_25

Durand J-L, Schaufele R, Gastal F. 1999. Grass leaf elongation rate as a function of developmental stage and temperature: morphological analysis and modelling. Annals of Botany 83: 577-588. https://doi. org/10.1006/anbo.1999.0864

Easton HS, Christensen MJ, Eerens JPJ, Fletcher LR, Hume DE, Keogh RG, Lane GA, Latch GCM, Pennell CGL, Popay AJ, Rolston MP, Sutherland BL, Tapper BA. 2001. Ryegrass endophyte: a New Zealand Grassland success story. Proceedings of the New Zealand Grassland Association 63: 37-46. https://doi.org/10.33584/jnzg.2001.63.2429

Easton HS, Amyes JM, Cameron NE, Green RB, Kerr GA, Norriss MG, Stewart AV. 2002. Pasture plant breeding in New Zealand: where to from here? Proceedings of the New Zealand Grassland Association 64: 173-179. https://doi.org/10.33584/ jnzg.2002.64.2455

Easton HS, Stewart AV, Kerr GA. 2011. Ryegrass in pastures-breeding for resilience. Grassland Research and Practice Series 11: 139-148.

Faville MJ, Crush JR, Hong W, Phillips H, Lee JM, Chapman D. 2020. Effects of pasture age on the genotype and phenotype of perennial ryegrass. Grass and Forage Science 75: 135-144. https://doi. org/10.1111/gfs.12474

Griffiths WM, Matthew C, Lee JM, Chapman DF. 2016. Is there a tiller morphology ideotype for yield differences in perennial ryegrass (Lolium perenne L.)? Grass and Forage Science 72: 700-713 https:// doi.org/10.1111/gfs.12268.

Hazard L, Ghesquiere M, Barraux C. 1996. Genetic variability for leaf development in perennial ryegrass populations. Canadian Journal of Plant Science 76: 113-118. https://doi.org/10.4141/cjps96-017

Hume DE, Sewell JC. 2014. Agronomic advantages conferred by endophyte infection of perennial ryegrass (Lolium perenne L.) and tall fescue (Festuca arundinacea Schreb.) in Australia. Crop \& Pasture Science 65: 747-757. https://doi.org/10.1071/ CP13383

Jahufer M, Luo D. 2018. DeltaGen: a comprehensive decision support tool for plant breeders. Crop Science 58: 1118-1131. https://doi.org/10.2135/ cropsci2017.07.0456

Jewiss OR. 1972. Tillering in grasses - its significance and control. Journal of the British Grassland Society 
27: 65-82. https://doi.org/10.1111/j.1365-2494.1972. tb00689.x

Lee JM, Matthew C, Thom ER, Chapman DF. 2012. Perennial ryegrass breeding in New Zealand: A dairy industry perspective. Crop and Pasture Science 63: 107. https://doi.org/10.1071/CP11282

Lee JM, Thom ER, Wynn K, Waugh D, Rossi L, Chapman DF. 2017. High perennial ryegrass seeding rates reduce plant size and survival during the first year after sowing: does this have implications for pasture sward persistence? Grass and Forage Science 72: 382-400. https://doi.org/10.1111/gfs.12243

Lee JM, Thom ER, Chapman DF, Wynn K, Waugh D, Rossi L, Faville MJ, Bell NL, McNeill MR. 2018. High perennial ryegrass seeding rates do not negatively impact pasture sward persistence. Grass and Forage Science 73: 456-472. https://doi. org/10.1111/gfs.12335

Malcolm B, Smith KF, Jacobs JL. 2014. Perennial pasture persistence: the economic perspective. Crop \& Pasture Science 65: 713-720. https://doi. org/10.1071/CP13419

Matthew C, Lemaire G, Hamilton NRS, Hernandezgaray A. 1995. A modified self-thinning equation to describe size/density relationships for defoliated swards. Annals of Botany 76: 579-587. https://doi. org/10.1006/anbo.1995.1135

Muylle H, Baert J, Van Bockstaele E, Moerkerke B, Goetghebeur E, Roldan-Ruiz I. 2005. Identification of molecular markers linked with crown rust (Puccinia coronata f. sp. lolii) resistance in perennial ryegrass (Lolium perenne) using AFLP markers and a bulked segregant approach. Euphytica 143: 135-144. https://doi.org/10.1007/s10681-005-3058-1

O'Connor J, Jahufer M, Lyons T. 2020. Examining perennial ryegrass (Lolium perenne L.) persistence through comparative genetic analyses of two cultivars after nine years in the field. Euphytica 216: 36. https://doi.org/10.1007/s10681-020-2568-1

Parsons A, Robson M. 1981a. Seasonal changes in the physiology of S24 perennial ryegrass (Lolium perenne L.) 3. Partition of assimilates between root and shoot during the transition from vegetative to reproductive growth. Annals of Botany 48: 733-744. https://doi.org/10.1093/oxfordjournals.aob.a086180

Parsons AJ, Robson MJ. 1981b. Seasonal changes in the physiology of S24 perennial ryegrass (Lolium perenne L.). 2. Potential leaf and canopy photosynthesis during the transition from vegetative to reproductive growth. Annals of Botany 47: 249258. https://doi.org/10.1093/oxfordjournals.aob. a086013

Parsons AJ, Edwards GR, Newton PCD, Chapman DF, Caradus JR, Rasmussen S, Rowarth JS. 2011. Past lessons and future prospects: plant breeding for yield and persistence in cool-temperate pastures. Grass and Forage Science 66: 153-172. https://doi. org/10.1111/j.1365-2494.2011.00785.x

Romera AJ, Doole GJ, Beukes PC, Mason N, Mudge PL. 2017. The role and value of diverse sward mixtures in dairy farm systems of New Zealand: An exploratory assessment. Agricultural Systems 152: 18-26. https://doi.org/10.1016/j.agsy.2016.12.004

Sartie AM, Easton HS, Matthew C. 2009. Plant morphology differences in two perennial ryegrass cultivars. New Zealand Journal of Agricultural Research 52: 391-398. https://doi. org/10.1080/00288230909510521

Tozer KN, Chapman DF, Bell NL, Crush JR, King WM, Rennie GM, Wilson DJ, Mapp NR, Rossi L, Aalders LT, Cameron CA. 2014. Botanical survey of perennial ryegrass-based dairy pastures in three regions of New Zealand: Implications for ryegrass persistence. New Zealand Journal of Agricultural Research 57: 14-29. https://doi.org/10.1080/002882 33.2013 .863785

Verdenal A, Combes D, Escobar-Gutiérrez AJ. 2008. A study of ryegrass architecture as a self-regulated system, using functional-structural plant modelling. Functional Plant Biology 35: 911-924. https://doi. org/10.1071/FP08050

VSN I. 2015. GenStat for Windows 18th Edition. Hemel Hampstead, UK.

Westoby M. 1984. The self-thinning rule. Advances in Ecological Research 14: 167-225. https://doi. org/10.1016/S0065-2504(08)60171-3

White J, Hodgson JG. 1999. New Zealand pasture and crop science: Oxford University Press.

Wilkins PW, Humphreys MO. 2003. Progress in breeding perennial forage grasses for temperate agriculture. Journal of Agricultural Science 140: 129150. https://doi.org/10.1017/S0021859603003058 